\title{
Detrimental effect of protracted hyperglycaemia on beta-cell neogenesis in a mouse murine model of diabetes
}

\author{
Y. Guz, A. Torres, G. Teitelman \\ Department of Anatomy and Cell Biology, State University of New York, Health Science Center at Brooklyn, \\ Brooklyn, New York, USA
}

\begin{abstract}
Aims/hypothesis. Previous studies have shown that new beta cells differentiate from intra-islet precursors in pancreatic islets of mice in which diabetes is induced by injecting a high dose of the beta-cell toxin streptozotocin. Moreover, the re-establishment of euglycaemia by insulin therapy 1 day after streptozotocin treatment improved the process of regeneration. We sought to assess whether a 1-week delay in the restoration of euglycaemia would affect beta-cell regeneration.

Methods. Adult CD-1 mice were injected with $200 \mathrm{mg} / \mathrm{kg}$ of streptozotocin. One group of mice remained hyperglycaemic throughout the experiment while a second group became normoglycaemic following the administration of insulin therapy 1 week after the injection of streptozotocin. Pancreata removed at different times after treatment were processed for visualization of $\beta$ precursor-cell markers and insulin by confocal microscopy.
\end{abstract}

Results. New beta cells appeared in islets of streptozotocin-treated mice after restoration of normoglycaemia. Like islets of streptozotocin mice in which blood glucose concentrations were rapidly restored, islets of mice that became normoglycaemic 1 week after streptozotocin treatment also had two potential insulin precursor cell types. Protracted hyperglycaemia however, had several harmful effects on insulin cell neogenesis, such as a reduction in the number of euglycaemic mice with successful beta-cell regeneration and a decrease in the number and survival of the newly differentiated insulin-containing cells.

Conclusion/interpretation. These results indicate that islets gradually lose their regenerative potential when they are exposed to high circulating glucose concentrations for an extended period of time. [Diabetologia (2002) 45:1689-1696]

Keywords Insulin cells, diabetes, regeneration, beta precursor cells, streptozotocin, islets of Langerhans.
There is currently an active search for sources of new beta cells that could be used to replace the original population destroyed by injury or disease $[1,2,3,4,5$, 6]. Pluripotent stem cells isolated from the duct or is-

Received: 27 June 2002 / Revised: 8 August 2002

Published online: 14 November 2002

(C) Springer-Verlag 2002

Corresponding author: Dr. G. Teitelman, Department of Anatomy and Cell Biology, State University of New York, Health Science Center at Brooklyn, 450 Clarkson Ave., Brooklyn, NY 11203, USA. E-mail: gteitelman@downstate.edu

Abbreviations: SZ, Streptozotocin; IN, insulin; SOM, somatostatin; Glut-2, glucose transporter-2; Glu, glucagon. lets were shown to be capable of self renewal and differentiation into insulin-producing cells in vitro $[4,5]$. Islets contain an additional source of $\beta$ precursor cells that differentiate in vivo after islet injury. We have reported that newly differentiated beta cells appeared in the pancreases of mice in which diabetes was induced by injecting streptozotocin (SZ), a beta-cell toxin [7]. The re-establishment of normal glucose concentrations by exogenously administered insulin 1 day after the injection of SZ led to an increase in beta-cell neogenesis and to the development of morphologically normal pancreatic islets [8], although the functional capacity of these cells has not been determined. Our results suggested that the new beta cells that appeared 
in islets of euglycaemic SZ mice were generated by at least two different sets of putative intra-islet beta precursor cells expressing embryonal traits. One group of progenitors expressed the glucose transporter 2 (GLUT2) while the second set of beta-cell progenitors coexpressed SOM and Pdx-1, a key transcription factor required for the development of the pancreas and for the regulation of insulin expression $[9,10]$. We postulated that both GLUT2 and Pdx-1/SOM+ cells matured into GLUT-2+ Pdx-1+ cells containing only insulin [8].

We sought to determine the effect of protracted hyperglycaemia on beta-cell neogenesis. The fact that prolonged exposure to high glucose concentrations is deleterious to beta-cell function [11, 12, 13] suggests that it could also be detrimental to beta-cell precursors, perturbing their differentiation into insulin-containing cells. To test this, we investigated whether new beta cells appeared in islets of mice that were injected with SZ, remained hyperglycaemic for 1 week and then were rendered normoglycaemic by injecting insulin. Our additional goals were to ascertain the contribution of the previously identified presumptive precursor cell types to beta-cell neogenesis and if these beta cells eventually formed new islets.

\section{Methods}

Animals and tissue processing. Six-week-old male CD-1 mice were obtained from Charles River (Wilmington, Mass., USA). Mice were injected intraperitoneally with $200 \mathrm{mg} / \mathrm{Kg}$ streptozotocin (SZ, Upjohn, Kalamazoo, Mich.; USB, Amersham, Arlington Heights, Ill., USA) in $0.1 \mathrm{~mol} / \mathrm{l}$ citrate buffer, $\mathrm{pH} 4.5$ after a 12-h overnight fast. The SZ solution was prepared before each individual injection. Control mice were injected with the equivalent volume of citrate buffer. Blood for measuring glucose was collected by snipping the tail in the fed state. Blood glucose was measured with Tracer II Blood Glucose monitor (Boehringer Mannheim Indianapolis, Ind., USA). After injecting SZ or diluent, animals were provided with Pedialyte, a paediatric electrolyte solution. We examined two groups of mice: (i) hyperglycaemic $(\mathrm{H})$ mice did not receive insulin treatment and therefore remained hyperglycaemic. They were examined 7, 9 and 14 days after the drug was injected. These mice were termed H-7, 9 and 14 days post SZ, respectively; (ii) normoglycaemic $(\mathrm{N})$ mice were injected with 2 to 3 units of NPH-ILETIN insulin (E. Lilly, Indianapolis, Ind., USA) ip. in the afternoon of the 6th day post SZ.

Animals with blood glucose (bg) concentrations between 80 and $130 \mathrm{~mol} / \mathrm{l}$ at 7 days post SZ were considered normoglycaemic. One group of normoglycaemic mice was killed at 7 days post SZ and the pancreas processed for histology and immunocytochemistry and evaluated for islet neogenesis. These mice were termed N-7 day post-SZ mice. Other normoglycaemic 7-day post-SZ mice were anaesthetized with Metofane (Schering-Plough, Union, N.J., USA), received 2 to 3 insulin implants (Linshit, Linshin Canada, Ontario, Canada) following the manufacturers instructions and were killed at 9 and 14 days after SZ was injected. These mice were termed $N 7$, 9 and 14 days post SZ respectively. Blood glucose (bg) concentrations were measured daily and only mice that remained normoglycaemic throughout the duration of the experiment were examined. At least six animals per group of $\mathrm{H}$ and $\mathrm{N}$ mice were evaluated for beta-cell neogenesis.

From the morning of day 1 post SZ until the end of the experiment, all SZ mice were fed with Pregestimil, (Mead Johnson, Evansville, Ind., USA), a hypoallergenic infant formula used to feed diabetic mice [14]. Mice were perfused through the heart with $4 \%$ paraformaldehyde buffered to $\mathrm{pH} 7.4$ with $0.1 \mathrm{~mol} / 1$ sodium phosphate buffer (PBS). The fixed tissues were infiltrated overnight in $30 \%$ sucrose, mounted in embedding matrix (Lipshaw, Pittsburgh, Pa., USA) and 15 to 20 um cryostat sections were collected onto gelatincoated slides. These studies were approved by the Animal Care and Use Committee of SUNY-Downstate Medical School and are in accordance with Federal and State of New York regulations and NIH guidelines.

Source of antibodies and purified peptides. For primary antiserum, guinea pig antibodies to bovine insulin and rat C-peptide were purchased from Linco Research (Eureka, Mo., USA). Rabbit antiserum to human glucagon was purchased from Calbiochem (San Diego, Calif., USA). Rabbit antisera to human PP and to somatostatin were supplied by Peninsula Labs (Belmont, Calif., USA). Mab antibody to human glucagon and insulin were purchased from Sigma (St. Louis, Mo., USA). Rabbit antisera to Nestin was generously provided by $\mathrm{Dr}$ M. Vallejo (UA, Madrid, Spain). Rabbit antisera to GLUT2 was purchased from Chemicon (Temecula, Calif., USA). Affinity purified antiserum to the N-terminal domain of Pdx-1 was a generous gift from C.V.E. Wright (Vanderbilt University, Nashville, Tenn., USA). Antibodies were used at the following dilutions: guinea pig anti-bovine insulin -1: 400; rabbit antisera to GLUT2 1:1000; rabbit anti-human glucagon-1: 12 000; rabbit anti-human somatostatin-1: 8000 for control sections and 1:20 000 for sections of SZ-treated pancreases; rabbit antihuman pancreatic polypeptide $-1: 100000$; rabbit anti-Nestin1:5000, rat anti-somatostatin 1:2000; Mab to glucagon 1:6000 and Mab to insulin 1:2000. Rabbit anti-mouse PDX-1 was used at a 1:8000 dilution. This antibody is highly specific for the nuclear form of Pdx-1. However, the high sensitivity of the confocal microscope allowed us to distinguish a weak cytoplasmic staining, which was not detected using a microscope with a conventional optical system [8].

For secondary antibodies, biotinylated goat anti-rabbit IgG and avidin-labelled peroxidase were purchased from Vector Laboratories (Burlingame, Calif., USA). Alexa Fluor 488 antimouse, anti-rat and anti-rabbit IgG, Alexa Fluor 594 anti-guinea pig, anti-rabbit and anti-mouse IgG were purchased from Molecular Probes (Eugene, Ore., USA). All secondary IgG's were used at 1:200 dilution for $1 \mathrm{~h}$. Sections labelled with fluorescent probes were covered with 2 to 3 drops of Prolong Antifade solution (Molecular Probes) after completion of the staining procedure and were dried at room temperature before examination.

Immunolabelling of cryostat sections using peroxidase techniques. These techniques have been described [7, 8]. In brief, the sections were incubated sequentially in an empirically derived optimal dilution of control serum or primary antibody raised in species " $\mathrm{X}$ " containing $1 \%$ goat serum in Tris-saline solution (TS; $0.9 \% \mathrm{NaCl}$ in $0.1 \mathrm{~mol} / \mathrm{l}$ Tris, $\mathrm{pH} 7.4$ ) for $18 \mathrm{~h}$; a $1: 50$ dilution of anti- (species $\mathrm{x}$ ) biotinylated $\mathrm{IgG}$ solution in $1 \%$ goat serum in TS for $30 \mathrm{~min}$; and a 1:100 dilution of peroxidase-avidin complex for $30 \mathrm{~min}$ (avidin-biotin complex: $\mathrm{ABC}$ technique). After these incubations, the bound peroxidase was visualized by 3,3'-diaminobenzidine (DAB). After the DAB step, sections were dehydrated and mounted with Permount. 


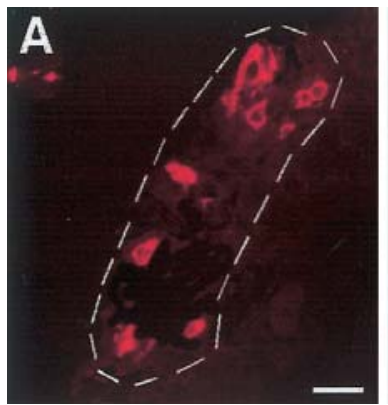

Fig. 1A-C. IN+ cells reappeared in islets after protracted hyperglycaemia. A Islet of a hyperglycaemic 7-day post-SZ mice illustrates the presence of few IN+ cells (red). Bar=35 um. B Photomicrograph of an islets of normoglycaemic 7-days postSZ mice. Note the large increase in the number of cells stained for insulin. Bar=20 um. In (A) and (B) the islet borders are indicated with dashed lines. $\mathbf{C}$ Islet of a normoglycaemic 7-day post-SZ mouse stained for IN (green) and PDX-1 (red) illustrates the presence of IN+ Pdx-1+ cells and of IN+ cells that do not express the homeoprotein (indicated by arrowheads). Bar $=15$ um

For double labelling, sections were first incubated with antisera to $\mathrm{Pdx}-1$ and the bound antibody was visualized by DAB (brown precipitate), followed by incubation with antisera to SOM, which was visualized with the blue reaction product of the Vector SG substrate (Vector Labs).

Confocal microscopy. An LSM 510 laser scanning confocal microscope (Zeiss) fitted with an Axiovert $100 \mathrm{M}$ microscope (Zeiss) was used with a $63 \times 1.4$ NA pan Apochromat objective (Zeiss). Excitation on LSM 510 unit was with a $15 \mathrm{~mW}$ argon ion laser running at $75 \%$ power emitting at $488 \mathrm{~nm}$, a $1.0-\mathrm{mW}$ helium/neon laser emitting at $543 \mathrm{~nm}$, and a $5.0 \mathrm{~mW}$ helium/ neon laser emitting at $633 \mathrm{~nm}$. Emissions were collected using a 505 to 530-nm band pass filter to collect Alexa green emissions and a 560 to $615-\mathrm{nm}$ band pass filter to collect Alexa red emissions. Typically, 1 um vertical steps were used with a vertical optical resolution of less than $1.0 \mathrm{um}$.

Determination beta-cell relative volume per islet and per tissue. To determine the beta-cell relative volume per islet, each gland was sectioned throughout its length to avoid bias due to regional variations in islet properties. Randomly chosen insulin-stained sections of pancreases of $\mathrm{N}$ and $\mathrm{H} \mathrm{7,9}$ and 14-day post-SZ mice, three pancreases per experimental group, were examined. Pancreases of normoglycaemic mice were first screened for the presence of GLUT-2+ cells, which is correlated with successful neogenesis. Other sections of those selected pancreases were stained for insulin and used to evaluate the relative beta-cell mass. The relative volume of beta cells per islet was measured by the point sampling method [15] using a 300 point ocular grid according to the formula: $\mathrm{F}=\mathrm{h} / \mathrm{n}$ in which $h$ was the number of "hits" over beta cells and $n$ was the number of points scored over islets [15]. The relative islet-cell mass per pancreas was measured using the same formula in which $n$ was the number of hits over exocrine tissue. In this study the absolute islet mass was not calculated because this measurement requires determining the weight of the gland before all liquids are removed. We found that even a short period without fixative solution during the critical initial period of fixation decreased the quality of cryostat sections and of the histological images.

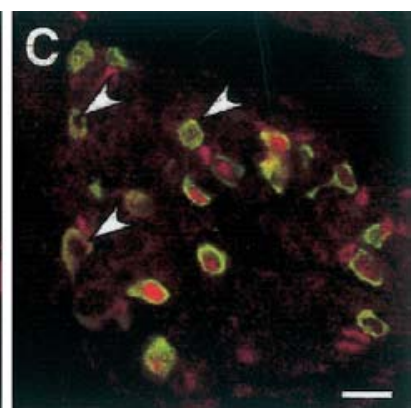

Tissues were examined with a Nikon Microphot SA microscope equipped with Nomarski optics and using a 10× ocular and $40 \times$ objective.

Statistical analysis. All values are shown as means \pm SE. For comparison between two groups, the unpaired Student's $t$ test was used. A $p$ value less than 0.05 was considered significant.

\section{Results}

Insulin-dependent increase in the number of beta cells. We previously showed that a dose of $200 \mathrm{mg} / \mathrm{Kg}$ of streptozotocin eliminated almost all the beta cells of islets a few hours after it was injected [8]. Few IN+ cells reappear in islets of hyperglycaemic (H) 7-day post-SZ mice (Fig. 1A). However, the induction of normoglycaemia by exogenously administered insulin increased the number of IN+ cells present in islets of normoglycaemic (N) 7-day post-SZ mice (Fig. 1B). Although some of these cells expressed Pdx-1, a subset of the newly differentiated IN+ cells did not contain the transcription factor (Fig. 1C). The percentage of normoglycaemic mice with pronounced islet-cell neogenesis was low, since only 7 out of $46(15 \%) \mathrm{N}-7$ day post-SZ mice had an increased number of IN+ cells in islets after normal blood glucose concentrations were re-established.

Morphometric studies indicated that the beta-cell volume per islet and per tissue was higher in 7-day post-SZ euglycaemic mice with successful neogenesis than in the mice with high circulating blood glucose concentrations (Figs. 2, 3). This analysis also confirmed a temporal decrease in the number of IN+ cells during insulin therapy. Thus, beta-cell volume per islet and the relative beta-cell mass decreased more than $50 \%$ from 7 to 14 days post SZ (Figs. 2, 3).

Source of newly differentiated beta cells. Next, we sought to determine the identity of the presumptive islet precursor cells that generated the newly differentiated IN+ cells. To ascertain whether the SOM/Pdx-1+ cells were involved in beta-cell neogenesis, the percentage of somatostatin cells that expressed PDX-1 was determined. The proportion of SOM/Pdx-1+ cells was higher in euglycaemic 7-day post-SZ mice than in mice that remained hyperglycaemic or in the control 


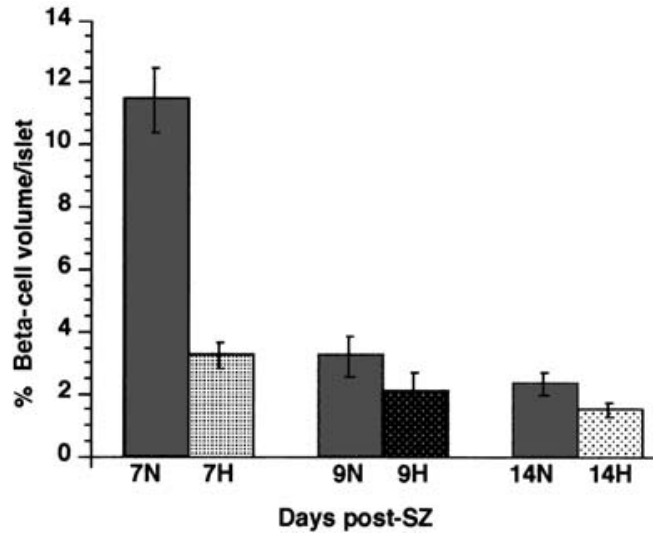

Fig. 2. Insulin injection promoted a transient increase in betacell volume per islet. Seven-day post-SZ mice were injected with SZ at day 1, with IN at day 6 and their blood glucose concentration was tested at day 7. A group of normoglycaemic 7-day post-SZ mice $(n=7)$ were killed and their pancreas examined. Other $7 \mathrm{~N}$ mice received insulin pellets and were examined 2 and 7 days later ( $9 \mathrm{~N}$ and $14 \mathrm{~N}$ respectively). Mice that did not receive insulin therapy remained hyperglycaemic and were examined at 7, 9 and 14 days post $\mathrm{SZ}$ injection $(7 \mathrm{H}, 9 \mathrm{H}$, $14 \mathrm{H}$ respectively). Randomly selected islets were analysed, three mice per group. At least 5000 points were scored for each group. The number of beta cells per islet area is expressed as means \pm SEM. Note that there is a threefold difference in the beta-cell volume per islets from $7 \mathrm{~N}$ and $7 \mathrm{H}$ mice $(p<0.001)$ and that the beta-cell volume in normoglycaemic mice decreased with time. $p$ of $9 \mathrm{~N}$ vs $9 \mathrm{H}$ and of $14 \mathrm{~N}$ vs $14 \mathrm{H}<0.05$

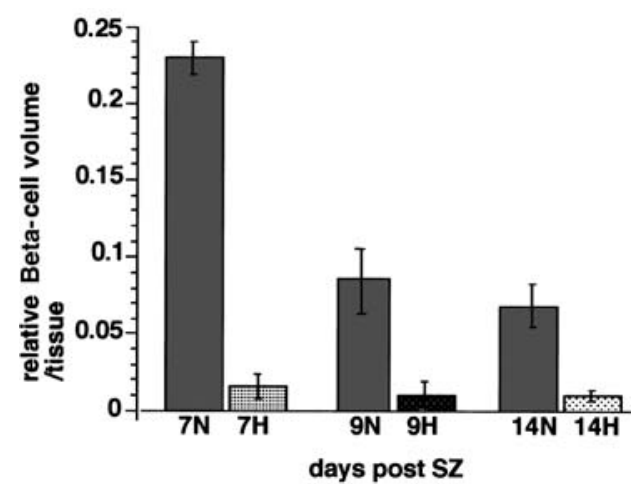

Fig. 3. The relative beta-cell volume per tissue decreased with time in normoglycaemic SZ-treated mice. The relative beta-cell volume was measured in randomly selected sections from three SZ mice per experimental group. Bar graphs indicate results for $7 \mathrm{~N}, 7 \mathrm{H}, 9 \mathrm{~N}, 9 \mathrm{H}$, and $14 \mathrm{~N}$ and $\mathrm{H}$. Over 5000 points were scored for 7-day post-SZ and 3000 for 9- and 14-day post-SZ mice. Values are expressed as means \pm SEM. At all stages examined, $p<0.001$ when $\mathrm{N}$ groups were compared to $\mathrm{H}$. Note a decrease in the relative beta-cell volume per tissue with time

mice (Fig. 4), indicating that the number of these cells increased after normal blood glucose concentration was re-established $[7,8]$. No difference was found in the percentage of Pdx-1/PP and Pdx-1/GLU between experimental mice and untreated control mice. Pancreatic islets of normoglycaemic 7-day post-SZ mice contained a small number of cells coexpressing IN and SOM (Fig. 5O, P).

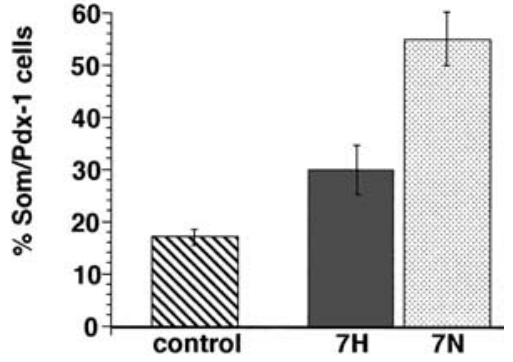

Fig. 4. The percentage of PDX-1/SOM+ cells increased in normoglycaemic SZ+IN treated mice. The percentage of Pdx-1/ SOM cells is compared between the control mice, $7 \mathrm{~N}$ and $\mathrm{H}$. Three pancreas were examined per group. Total number of cells scored for the Pdx-1/SOM combination in control mice, $7 \mathrm{~N}$ and $7 \mathrm{H}$ was 2549 from 35 islets, 2231 from 41 islets and 1947 from 64 islets respectively. The number of Pdx-1/SOM cells is expressed as the means \pm SEM. $p<0.001$ when $7 \mathrm{~N}$ was compared with the control mice or to $7 \mathrm{H}$

Islets of hyperglycaemic 7-day post-SZ mice contained few GLUT-2+ cells (Fig. 5A-C) and the number of cells expressing the transporter increased after normal blood glucose concentrations were restored as in our previous observations [8]. However, the number of GLUT-2+ cells increased in only $15 \%$ of the normoglycaemic mice. These were the mice that at-

Fig. 5A-P. Source of neoformed beta cells. A-C are photomicrograph of a representative islet of an $\mathrm{H}-7$ day post-SZ mouse. Note the presence of few IN+ cells (red) and the faint GLUT-2 staining (green). Bar: $30 \mathrm{um}$. D-F illustrate an islet of N-7 day post-SZ mouse. A large number of IN (D, red), Glut-2 $(\mathbf{E}$, green) and IN/GLUT/2 $(\mathbf{F})$ cells reappear in pancreas after normoglycaemia was re-established. Note that a subset of GLUT-2+ cells coexpress IN. Two of these double label cells are indicated with a small and large arrow respectively. Most of the IN/GLUT-2 cells have low concentrations of GLUT-2 expression. Presumably these cells were in the process of translocating GLUT-2 from the cytoplasm to the cell membrane. Bar: 20 um. G High power magnification of the cell illustrated with an arrow in (E) shows the presence of GLUT-2 staining in the cell membrane. Bar=5 um. H Photomicrograph of embryonic pancreas at day 17 of gestation stained for GLUT-2 (green). Some of the cells have cytoplasmic staining (small arrow) while in others the transporter is localized to the cell membrane (large arrow). Bar= 15 um. I Photomicrograph of a representative islet of a control mouse that was stained for GLUT-2 (green). Note that most cells have the transporter localized to the cell membrane. Bar=20 um. J-L Photomicrograph of an islet of islet of a N-9 day post-SZ mouse. Note a decrease in the number of IN+ cells (J) but not of the GLUT-2+ cells (K) when compared to (D) and (E) respectively. $\mathbf{L}=\mathbf{J}+\mathbf{K}$. Bar: $20 \mathrm{um}$. $\mathbf{M}$ Photomicrograph of an islet of a N-7 day post-SZ mice stained for GLUT-2 (green). The islet is indicated with a dashed line. Note the absence of GLUT-2+ cells. This and similar islets contained few IN+ cells. Bar=40 um. $\mathbf{N}$ shows a section of a N-7 day post-SZ mouse stained for IN (red) and Nestin (green). This photomicrograph documents that IN+ cells that reappear in islets do not express Nestin. Bar: 50 um. O, P Photomicrograph of an islet from a N-7 day post-SZ mouse illustrates the presence of IN/SOM+ cells (arrowheads). O IN, P SOM. Bar: 15 um 
tained successful beta-cell regeneration. In these mice, most, if not all of the newly differentiated IN+ cells co-expressed GLUT-2 (Fig. 5D-F). In some IN cells the transporter was localized to the cell membrane (Fig. 5E, G) while in others it was present at low concentrations in the cytoplasm (Fig. 5E). The movement of the transporter from the cytoplasm to the cell membrane is probably correlated with islet cell maturation. In islets of embryos, some cells contained GLUT-2 in the cytoplasm while in other cells the transporter was found in the membrane (Fig. 5H). In contrast, islet cells of adults showed only membrane localization of
GLUT-2 (Fig. 5I), confirming previous observations [8]. The fact that many beta cells of regenerating islets expressed GLUT-2 in the cytoplasm supports the view that these cells failed to achieve a mature phenotype. The percentage of GLUT-2 cells expressing IN decreased from day $7(38.5 \pm 4.1, n=10)$ to 9 post-SZ days post SZ $(5.88 \pm 0.75, n=10)$ (Figs. 2, 3 and Fig. 5J-L) indicating that factors required for sustaining long term expression of insulin were missing after protracted hyperglycaemia.

In contrast to mice that showed beta-cell neogenesis, a majority of mice that attained normoglycaemia
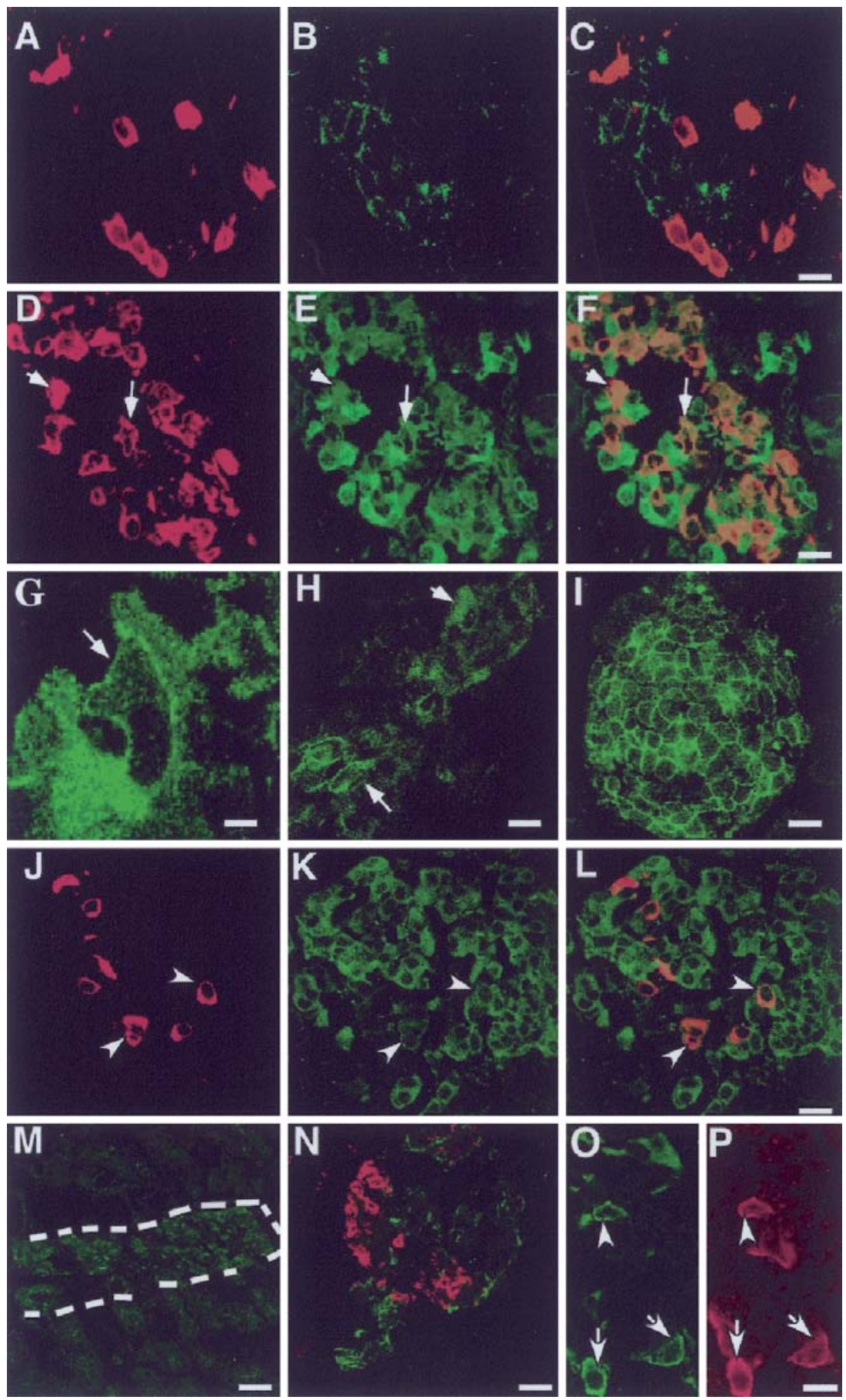


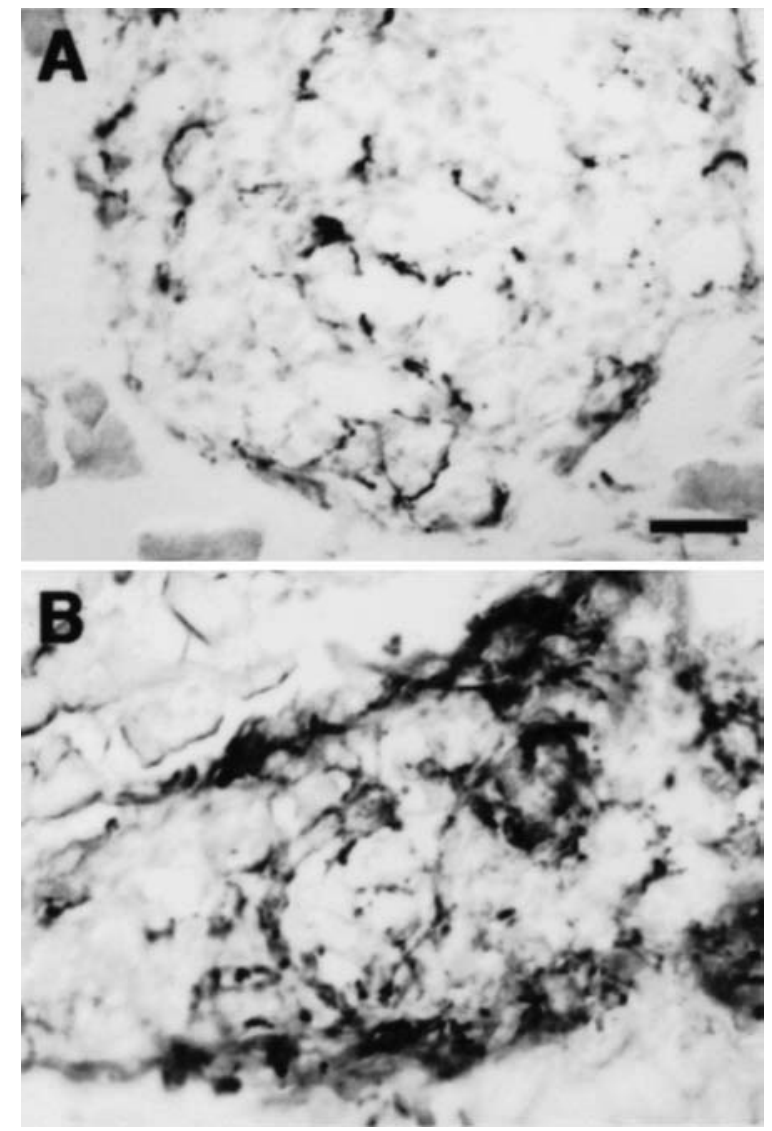

Fig. 6A, B. Nestin immunoreactivity increased in SZ-treated islets. Photomicrographs illustrates nestin immunoreactivity in control (A) and in a SZ-treated islet (B) of a N-7 day SZmouse. Note that nestin staining increased after treatment with the toxin. Bar=60 um

at 7 days post-SZ after insulin therapy lacked GLUT-2 (Fig. 5M) and GLUT-2/IN+ cells but contained few cells expressing only insulin. The beta-cell mass of islets of normoglycaemic mice with poor regeneration was similar to that of hyperglycaemic mice. These observations indicate a correlation between the failure of GLUT-2 cells to differentiate and the lack of beta-cell neogenesis. These findings also suggest that the GLUT-2 cells that reappeared in islets after the restoration of normal blood glucose concentrations generated most of the newly differentiated beta cells. In addition to the cell types mentioned above, islets contained GLUT-2+/GLU cells, a cell type also found in embryos. These cells, like those that appeared in SZ mice that underwent only a brief hyperglycaemic period [8], were probably $\alpha$ cells that re-expressed an embryonic phenotype after SZ and IN treatment. In contrast to GLU cells, SOM and PP cells did not express GLUT-2 after SZ treatment.

Another presumptive precursor cell type present in islets are cells expressing the neural stem-cell marker nestin, which generate IN+ cells in culture [5]. We confirmed the presence of nestin+ cells (Fig. 6A) and determined that nestin immunoreactivity increased in islets after SZ treatment in both normoglycaemic (Fig. 6B) and hyperglycaemic mice, resembling the reaction of glial cells to injury [16]. In contrast to the observations in vitro, the newly differentiated IN+ cells that differentiated after SZ treatment did not contain nestin (Fig. 5N), suggesting that the beta cells that reappear in vivo were not produced by cells expressing this neural stem-cell marker.

\section{Discussion}

We sought to elucidate whether delayed normalization of blood glucose concentrations in diabetic mice would prevent beta-cell neogenesis. We found that new beta cells appeared in islets of mice that became normoglycaemic 7 days after injecting streptozotocin and that the relative beta-cell mass in these mice $(0.23 \pm 0.04)$ was similar to that of mice in which normoglycaemia was established 1 day after the injection of the toxin $(0.20 \pm 0.028,[8])$. This indicates that the population of $\beta$ precursor cells present in islets retained the ability to differentiate into insulin cells during a 1-week exposure to high glucose concentrations and did so soon after the animals became euglycaemic. However, the number of new beta cells per islet and the relative beta-cell mass in islets of SZ mice that became euglycaemic at 7 days post-SZ decreased with time in spite of the maintenance of normal blood glucose concentrations by continuous insulin therapy. In contrast, the relative beta-cell mass in the pancreases of mice exposed to hyperglycaemia for only 1 day increased significantly with time [8]. These observations indicate that the fate of the newly differentiated IN cells was determined by the length of the hyperglycaemic period that preceded their appearance.

The presence of sustained hyperglycaemia preceding the restoration of normal blood glucose concentrations also had a detrimental effect on the number of normoglycaemic 7-day post-SZ mice that showed successful regeneration. Thus, only $15 \%$ of these mice had islets containing 5 to 60 insulin cells while over $60 \%$ of the mice exposed for only $24 \mathrm{~h}$ to hyperglycaemia had successful beta-cell regeneration [8]. Taken together, these findings suggest that the extended period of hyperglycaemia before euglycaemia was established by insulin therapy inhibited beta-cell neogenesis in most SZ mice and failed to support beta-cell survival and growth in those 7-day post-SZ mice with successful regeneration. These observations support recent reports indicating that circulating blood glucose concentrations also play a critical role in beta-cell survival in transplanted islets [16]. Taken together, these results emphasize the critical role played by the fast restoration of normoglycaemia by insulin therapy in the appearance and fate of beta cells in adult mice.

The demise of the newly differentiated IN+ cells in mice rendered normoglycaemic 1 week after SZ treat- 
ment could be due a toxic effect of SZ to multiple organs leading to systemic imbalances and/or to specific deficiencies in the pancreas. Hyperglycaemia has a deleterious effect on both exocrine [17] and neuronal tissues [18], that could perturb interactions required for survival of the regenerating islets. Peri-islet Schwann cells could also play a role in the success of beta-cell regeneration. These cells become reactive after SZ-induced islet injury [19] and activated Schwann cells secrete cytokines [20] that could tamper precursor cell differentiation. Moreover, the death of the newly differentiated beta cells could be due to non-reversible damage in the vascular system caused by long-term exposure to high circulating blood glucose concentrations [21, 22, 23].

We previously proposed that islets contained two different sets of intra-islet precursor cells, the Pdx$1 / \mathrm{SOM}+$ and the GLUT-2+ cells. In agreement with our previous observations $[7,8]$, we found that hyperglycaemic mice contained Pdx-1/SOM cells and that the percentage of these cells increased after euglycaemia was restored. In normoglycaemic 7-day post SZ-mice, a small subset of SOM also contained IN. These cells were presumably generated by $\mathrm{Pdx}-1 /$ SOM cells that initiated IN expression. Hyperglycaemic mice also contained SOM/IN cells after protracted hyperglycaemia [7], indicating that the activation of IN expression by SOM cells is not inhibited by high circulating glucose concentrations. However, the small number of SOM-IN cells found in islets of normoglycaemic 7-day post-SZ mice suggest that these cells were not the primary source of beta cells in this model of islet regeneration. A second population of IN+ cells did not express Pdx-1. These IN+Pdx-1cells were probably generated by a different set of precursor cells that lacked the transcription factor and failed to acquire a mature phenotype.

In contrast to the Som/Pdx-1+ cells, the population of GLUT-2 precursor cells seems to play a crucial role in the generation of new beta cells. Normoglycaemic 7-day post-SZ mice that lacked GLUT-2 cells contained few IN+ cells, probably generated by $\mathrm{SOM} / \mathrm{Pdx}-1+$ precursors. Conversely, the subset of normoglycaemic mice with successful beta-cell regeneration contained numerous GLUT-2+ cells in their islets, indicating a direct correlation between the differentiation of cells containing the transporter and beta-cell neogenesis. However, the percentage of GLUT-2+ cells expressing IN decreased with time after restoration of normoglycaemia, suggesting that while GLUT-2 is required for the initiation of IN expression, other factors are necessary to sustain the expression of the hormone in GLUT-2+ cells.

The GLUT-2/IN cells present in islets of normoglycaemic 7-day post-SZ mice resembled the GLUT-2 cells of embryos. In the developing pancreas, GLUT-2 cells were characterized by abundant cytoplasmic expression of the transporter $[8,24]$. During islet cell mat- uration, the GLUT-2 expression translocated to the cell membrane of beta cells while its expression in alpha cells was inhibited [8]. Similarly, GLUT-2 expression in SZ mice that achieved normoglycaemia was initially localized to the cytoplasm. In mice exposed to a short (1 day) hyperglycaemic episode, the number of IN+ cells expressing GLUT- 2 in the cell membrane increased with time after normoglycaemia was re-established, indicating that these cells were undergoing a process of maturation [8]. In contrast, islets of normoglycaemic 7-day post-SZ mice contained few IN cells expressing GLUT-2 in the cell membrane and their number decreased with time. These observations indicate that most GLUT-2/IN cells of islets of mice that became euglycaemic by insulin therapy 1 week after SZ treatment failed to achieve a mature beta-cell phenotype.

Although the GLUT-2 and the Pdx-1/SOM cells were the only beta-cell precursors identified in the SZ model of islet regeneration, other progenitor cells could have also contributed to beta-cell neogenesis. It is possible that cells present in the exocrine compartment migrated into the islets and differentiated into beta cells or, alternatively, that acinar cells differentiated into islet cells, as reported in other models of beta-cell regeneration $[25,26]$. It is also conceivable that islets contain a recently discovered population of undifferentiated precursor cells expressing the transcription factor Ngn3 [27] and that these cells generate new beta cells during regeneration. Finally, it is possible that the GLU cells that initiate GLUT-2 expression after SZ and IN treatment downregulate glucagon expression and initiate insulin synthesis. The fact that islets did not contain IN/GLU cells, which would be expected to be an intermediate cell type appearing during this conversion, argues against this possibility. However, alpha cells expressing GLUT-2 could initiate insulin expression only after glucagon expression is turned off, which would account for the lack of cells co-expressing two hormones in the regenerating islets.

In conclusion, our results indicate that islets contain beta-cell precursors that retain the ability to differentiate into beta cells even after prolonged hyperglycaemia. However, the presence of high glucose concentrations for an extended period negatively affects the conditions that allow survival of the newly differentiated beta cells.

Acknowledgements. This work was supported by NIH grant DK-53870.

\section{References}

1. Bonner-Weir S, Taneja M, Weir GC et al. (2000) In vitro cultivation of human islets from expanded ductal tissue. Proc Natl Acad Sci USA 97: 7999-8004

2. Baxter LA, Schuppin GT, Smith FE (1993) A second pathway for regeneration of adult exocrine and endocrine pancreas: a possible recapitulation of embryonic development. Diabetes 42: 1715-1720 
3. Rosenberg L (1995) In vivo cell transformation: neogenesis of beta cells from pancreatic ductal cells. Cell Transplant 4: 371-383

4. Ramiya VK, Maraist M, Arfors KE, Schatz DA, Pech AB, Cornelius JG (2000) Reversal of insulin-dependent diabetes using islet generated in vitro from pancreatic stem cells. Nat Med 6: 278-282

5. Zulewski H, Abraham EJ, Gerlach MJ et al. (2001) Multipotential nestin-positive stem cells isolated from adult pancreatic islets differentiate ex vivo into pancreatic endocrine, exocrine and hepatic phenotypes. Diabetes 50: 521-533

6. Vinik A, Rafaeloff R, Pittenger G, Rosenberg L, Duguid W (1997) Induction of pancreatic islet neogenesis. Horm Metab Res 29: 278-293

7. Fernandes A, King LC, Guz Y, Stein R, Wright CVE, Teitelman G (1997) Differentiation of new insulin producing cells is induced by injury in adult pancreatic islets. Endocrinology 138: 1750-1762

8. Guz Y, Nasir I, Teitelman G (2001) Regeneration of pancreatic $\beta$ cells from intra-islet precursor cells in an experimental model of diabetes. Endocrinology 142: 4956-4968

9. Gannon M, Wright CVE (1999) Endodermal patterning and organogenesis. In: Moody S (ed.) Cell lineage and determination. Academic Press, London New York San Diego, pp 583-615

10. Edlund H (1998) Transcribing pancreas. Diabetes 47: 18171823

11. Robertson RP, Harmon J, Tanaka Y et al. (2000) Glucose toxicity of the $\beta$ cell: cellular and molecular mechanisms. In: Le Roith D, Taylor SI, Olefsky JM (eds) Diabetes mellitus. A fundamental and clinical test, 2nd edn. Williams and Wilkins, Lippincott, pp 105-115

12. Zangen DH, Bonner-Weir S, Lee CH et al. (1997) Reduced insulin, GLUT2, and IDX-1 in $\beta$ cells after partial pancreatectomy. Diabetes 46: 258-264

13. Jonas JC, Sharma A, Hasenkamp W et al. (1999) Chronic hyperglycemia triggers loss of pancreatic $\beta$ cell differentiation in an animal model of diabetes. J Biol Chem 274: 14112-14121

14. Coleman DL, Kuzava JE, Leiter EH (1990) Effect of diet on incidence of diabetes in nonobese diabetic mice. Diabetes 39: 432-436

15. Hellestrom C (1997) Growth pattern of pancreatic islets in animals. In: Volk BV, Wellman KE (eds) The diabetic pancreas, 1st edn. Plenum Medical Book Co, New York London, pp 61-97
16. Biarnes M, Montolio M, Nacher V, Raulrell M, Soler J, Montanya E (2002) $\beta$ cell death and mass in syngeneically transplanted islets exposed to short- and long-term hyperglycemia. Diabetes 51: 66-72

17. Williams JA, Goldfine ID (1993) The Insulin-Acinar relationship. In: Go VLW, Dimagno EP, Gardner JD, Lebernthal E, Reber HA, Scheele GA (eds) The pancreas, biology, pathobiology, and disease, 2nd edn. Raven Press, New York, pp 789-802

18. Greene DA, Lattimer SA, Sima AAF (1988) Pathogenesis and prevention of diabetic neurophathy. Diabetes Metab Rev 4: 201-221

19. Teitelman G, Guz Y, Ivkovic S, Ehrlich M (1998) Islet injury induces neurotrophin expression in pancreatic cells and reactive gliosis of peri-islet Schwann cells. J Neurobiology 34: 304-318

20. Rutkowski JL, Tuite GF, Lincoln PM, Boyer PJ, Tennekoon GI, Kunkel SL (1999) Signals for proinflammatory cytokine secretion by human Schwann cells. Neuroimmunology 101: 47-60

21. Sandler S, Jansson L (1985) Vascular permeability of pancreatic islets after administration of streptozotocin. Virchows Arch 407: 359-367

22. De Papae ME, Corriveau M, Tannous WN, Seemayer TA, Colle E (1992) Increased vascular permeability in pancreas of diabetic rats: detection with high resolution protein-A gold cytochemistry. Diabetologia 35: 1118-1124

23. Carlsson PO, Flodstrom M, Sandler S (2000) Islet blood flow in multiple low dose sterptozotocin-treated wild type and inducible nitric oxide synthetase-deficient mice. Endocrinology 141: 2752-2757

24. Pang K, Mukonoweshuro CH, Wong GG (1992) Beta cells arise from glucose transporter type 2 (GLUT-2)-expressing epithelial cells of the developing rat pancreas. Proc Natl Acad Sci USA 91: 9559-9563

25. Rooman I, Lardon J, Bowens L (2002) Gastrin stimulates $\beta$ cell neogenesis and increases islet mass from transdifferentiated but not from normal exocrine pancreas tissue. Diabetes 51: 686-690

26. Rooman I, Hereman Y, Heimberg H, Bowens L (2000) Modulation of rat pancreatic acinoductal transdifferentiation and expression of Pdx-1 in vitro. Diabetologia 43: 907-914

27. Gu G, Dubauskaite J, Melton DA (2002) Direct evidence for the pancreatic lineage: $\mathrm{Ngn} 3+$ cells are islet progenitors and are distinct from duct progenitors. Development 129: 2447-2457 